\title{
Evaluation of Testing of Serum Survivin and Alpha Fetoprotein in Patients with Hepatocellular Carcinoma and Hepatitis C Viral Infection
}

\author{
Usama Shaalan ${ }^{1}$, Ahmed Sharawy ${ }^{2}$, Mohamad Othman $^{1}$, and Hani Elharoun ${ }^{* 2}$. \\ 1/ Molecular diagnostics and Therapeutics department, Genetic Engineering and Biotechnology \\ Research Institute (GEBRI), University of Sadat City, Egypt \\ 2/ Clinical Pathology Department, National Liver Institute, Menofia University \\ Corresponding author: email ramohani@ hotmail.com
}

\begin{abstract}
Survivin is specific antiapoptotic gene product expressed in a variety of human neoplasmswhose overexpression might assist in early diagnosis and as a prognostic marker. The aim was to evaluate the plasma levels of survivin and alpha fetoprotein in patients with chronic hepatitis $C$ viral infection (HCV) with and without hepatocellular carcinoma (HCC). 70 subjects were divided into: a control group (Group I) ( 20 healthy volunteers ) and two patients groups: Group II, HCV group (20 patients); and Group III, HCC with $\operatorname{HCV}(30$ patients). Thorough physical examination, ultrasonography of the abdomen, laboratory investigations (liver profile, anti-HCV antibodies, hepatitis B surface antigen, Alpha fetoprotein (chemiluminometry) and Survivin (ELISA)) were performed. There was a significant increase in survivin level in HCV patients (Group II) when compared to the control group ( $p=0.039)$, along with a significant increase in AFP in Groups II and III when compared to Group I ( $\mathrm{P}<0.001$ for both). AFP also distinguished between the two HCV groups. The best generated cut off value for AFP was $10.9 \mathrm{ng} / \mathrm{ml}$ and for survivin $13.7 \mathrm{pg} / \mathrm{ml}$. Serum survivin diagnostic sensitivity was $\mathbf{5 3 . 3} \%$, diagnostic specificity $\mathbf{6 2 . 5 \%}$ and efficiency $\mathbf{5 8 . 6 \%}$, in contrast to $100 \%, 92.5 \%$ and $95.7 \%$, respectively, for AFPWhile survivin showed significant increase in the HCV group, its diagnostic performance was lower and it proved to be less reliable as a tumor marker for HCC than did AFP.
\end{abstract}

Keywords: Apoptosis - survivin - hepatocellular carcinoma - alpha fetoprotein.

\section{Introduction}

Apoptosis is a tightly regulated process that involves complex signaling pathways and cascades of molecular events needed for proper development during embryonic and fetal growth where there is destruction and reconstitution of cellular structures. In adults, apoptosis is needed to maintain differentiated tissues, elimination of aged cells without disrupting cellular integrity. (Bokerawa et al., 2005; Ye et al., 2007).

The suppression of apoptosis is thought to contribute to carcinogenesis due to several mechanisms ; including unusually prolonging of cellular lifespan, facilitating the accumulation of gene mutations and permitting growth factor-independent cell survival (Mamori et al., 2007). In addition, since the host's immune system normally eliminates cancer cells by induction of apoptosis, inhibition of this process is critical for cancer survival. It has been shown that the "Inhibitors of Apoptosis Proteins"'(IAP) are crucial regulators in the molecular mechanisms of apoptosis (Ito et al., 2000; Mamori et al., 2007).

Survivin, NIAP, c IAP1, c IAP 2, XIAP, Ts XIA, MLIAP and Apollon are IAP family members , and Survivin being the smallest member (Fields et al., 2004; Bokerawa et al., 2005). Survivin also known as Birc 5, 142 amino acid, is a bifunctional protein that regulates cell division and suppresses apoptosis (Bokerawa et al., 2005; Duffy et al., 2007).

Survivin is unique among the IAP proteins not only because it exhibits cell cycle-regulated expression that peaks at mitosis, but also, because it is undetectable in the majority of normal adult tissues except for placenta, thymus, spleen, testes, colonic crypts, primitive hematopoietic cells, T lymphocytes, neutrophils and vascular endothelial cells. It may regulate their proliferation or survival (Altieri et al., 1999; Sarela et al., 2000; Chang et al., 2004; Fields et al., 2004; Fukuda et al., 2006; Duffy et al., 2007; Ye et al., 2007). Also survivin is essential for angiogenesis; a fundamental process in tissue regeneration (Chiou et al., 2007).

Survivin is abundantly expressed in transformed cells and a variety of human cancers (Kappler et al., 2001; Ikeguchi et al., 2002; Fields et al., 2004; Wang et al., 2004; Asanuma et al., 2005; Vetter et al., 2005). The potential utility of survivin overexpression in early diagnosis and as a prognostic marker of cancer is controvertible (Kappler 


\section{Research Journal of Applied Biotechnology (RJAB)}

et al., 2001)

It has also been shown that Survivin inhibits apoptosis in cells exposed to diverse apoptotic stimuli by associating with microtubules of the mitotic spindle and inhibiting caspase activity. However, the biological functions of survivin, other than its antiapoptotic effect, are not well understood in human cancers (Kobayashi et al., 2002).

Expression of Survivin may be of prognostic significance and therapeutic relevance in many cancers.

The overexpression of Survivin in some cancer types can correlate positively with poor clinical prognosis ,increased rate of tumor recurrence and resistance to chemotherapy but does not correlate with overall survival (Kappler et al., 2001).

Anti-survivin therapies may potentiate chemotherapies that stimulates apoptosis by removal of the anti-apoptotic effect of Survivin and may also exert an anti-proliferative effect (Kappler et al., 2001).

Hepatocellular carcinoma (HCC), a major health problem worldwide, is one of the most common primary neoplasm of the liver and one of the most common solid tumors in the world (3). More than 500,000 new cases were diagnosed each year (Di Maio et al., 2008). HCC accounts for between $85 \%$ and $90 \%$ of primary liver cancer (Parkin, 2000). It is the fifth most common cancer worldwide and the third most common cause of cancer mortality (Bosch et al., 2005). In Egypt, HCC was reported to account for about $4.7 \%$ of chronic liver disease patients (El-Zayadi et al., 2001).

The most common condition associated with hepato carcinogenesis is cirrhosis which develops 20 to 40 years of chronic liver disease. Major causes of cirrhosis in patients with HCC include hepatitis B, hepatitis C, alcoholic liver disease and possibly nonalcoholic steato hepatitis. (12) It has been reported that not only increased cellular proliferation but also, diminished cell death play important roles in hepato carcinogenesis and tumor progression in HCC (Befeler et al., 2001).

Hepatocellular carcinoma develops from transformed hepatocytes during the course of chronic liver diseases . The activation of mitogenic oncogenes which is important for deregulated proliferation of hepatocytes, has been shown to enhance apoptosis. Therefore, resistance to apoptosis may provide a selective advantage factor for growth and progression of HCC. However, cellular mechanisms that inhibit apoptosis in HCC are not well understood (Ikeguchi et al., 2002) .

In HCC patients, Survivin expression has been frequently studied at cellular level and in tissues, but to our knowledge, little is known about its plasma level in such a disease (Ye et al., 2007; Hui et al., 2008).

The present work aimed at evaluating the plasma level of Survivin in Egyptian patients with HCC associated with hepatitis $\mathrm{C}$ infection and to compare it with its level in patients with chronic hepatitis $\mathrm{C}$ infection. The diagnostic performance of Survivin, as a possible tumor marker, will also be compared to that of serum Alpha fetoprotein.

\section{Materials and Methods}

This study was conducted on 70 subjects, after taking their consents, consequtively collected from the Medical and Oncology Departments of the Medical Research Institute, Alexandria Egypt divided into 2main groups: Control group (GroupI) included 20 apparently healthy volunteers and Patients groups(Group II and III) :

Group II : Hepatitis C viral infection group (20 patients) with HCV.

Group III: Hepato cellular carcinoma group (3 patients) with HCC on top of HCV infection.

Patients with rheumatoid arthritis, hepatitis B viral infection or other malignancies were not included .

To all the studied subjects thorough physical examination was done.All patients were classified using Child- Pugh score (Feldman et al., 2002) and ultrasonography of the abdomen were done. Laboratory investigations included: complete blood picture and plasma prothrombin activity (Lewis et al., 2001), fasting serum glucose (Trinder et al..1969), creatinine, protein ,albumin, total and direct bilirubin levels in addition to aminotransferases, alkaline phosphatase and gamma glutamyl transferase activities. Patients were screened for Rheumatoid factor, anti-HCV antibodies ,hepatitis B surface antigen, Schistosomal antibodies (Burtis et al., 2006). Alpha fetoprotein was performed by chemiluminometric method and Survivin by ELISA (Bishop et al., 2005).

\section{Results}

The control group included twenty apparently healthy volunteers (14 males and 6 females) their median age was 48.50 years (range $=40-62$ years) . The hepatitis $C$ viral infection group (Group II) included twenty patients suffering from chronic HCV infection (12 males and 8 females) their median age was 50 years (range $=40$ 67years). The hepatocellular carcinoma group (Group III) included thirty patients suffering from HCC associated with $\mathrm{HCV}$ infection (23 males and 7 females) their median age was 55 years (range=38-72years).

\section{Ultrasonographic findings in the studied groups:}

In HCV patients group (Group II): 9 out of 20 (45\%)

had enlarged liver with cirrhotic changes, 1 out of $20(5 \%)$

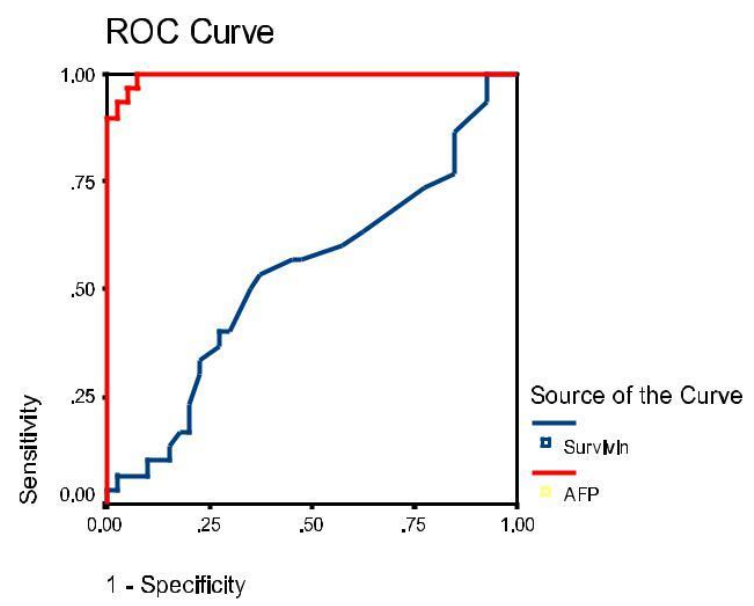


Research Journal of Applied Biotechnology (RJAB)

Table 1. Complete Blood Picture and Prothrombin Activity in the Studied Groups

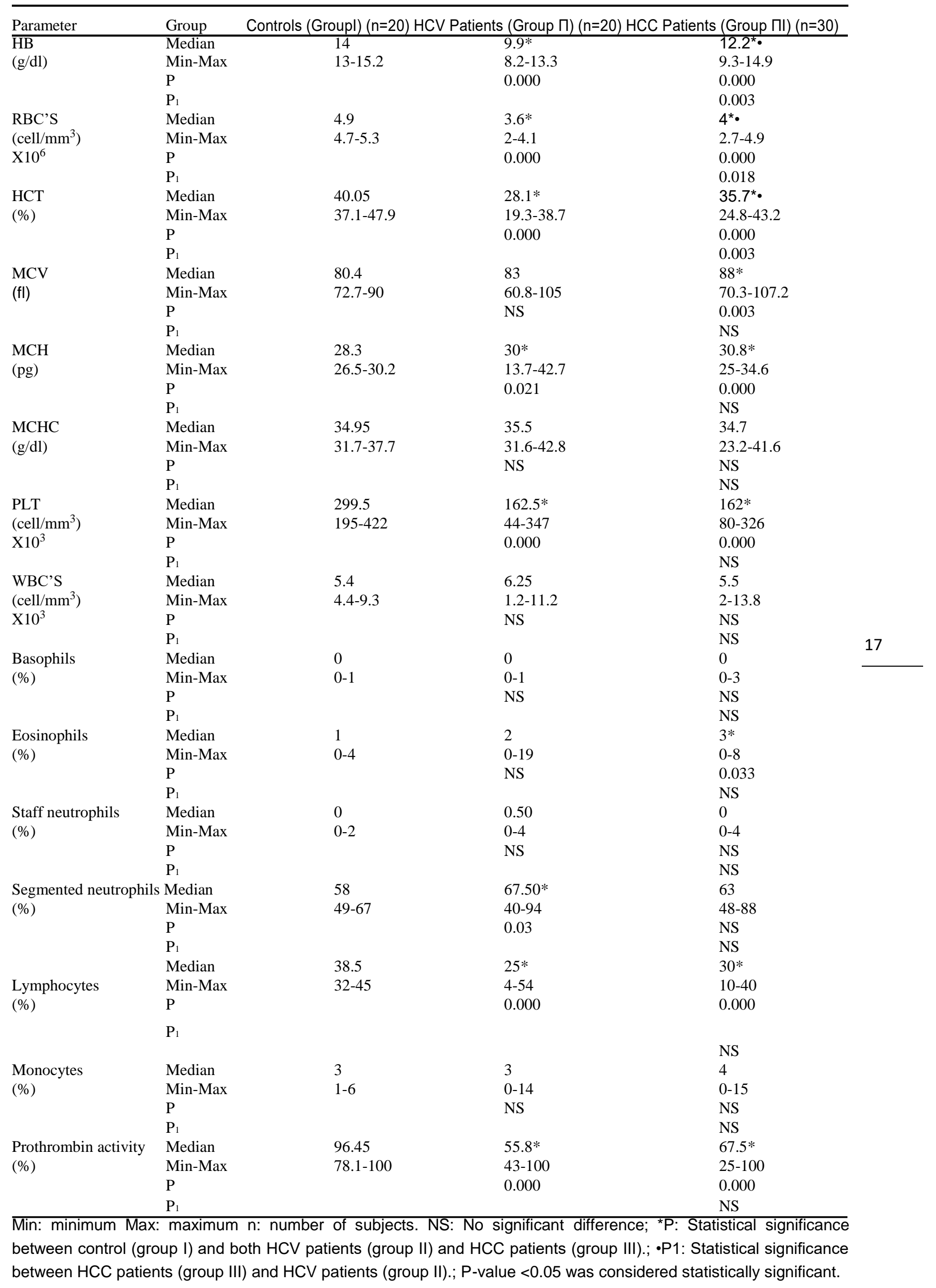


Research Journal of Applied Biotechnology (RJAB)

Table 2. Serum Values of Fasting Serum Glucose (FSG), Creatinine(Cr), Total Protein (TP) and Albumin (Alb) of the Studied Groups

\begin{tabular}{|c|c|c|c|c|}
\hline Parameter & Group & Controls (Group I) $(n=20)$ & HCV Patients (Group II) $(n=20)$ & HCC Patients (Group III) $(n=30)$ \\
\hline$\overline{\mathrm{FSG}}$ & Median & 89 & $102^{*}$ & $98.5^{\prime \prime}$ \\
\hline \multirow[t]{3}{*}{$(\mathrm{mg} / \mathrm{dl})$} & Min-Max & $76-97$ & $59-347$ & $66-205$ \\
\hline & $\mathrm{P}$ & & 0.018 & 0.03 \\
\hline & $\mathrm{P}_{1}$ & & & NS \\
\hline \multirow{4}{*}{$\begin{array}{l}\text { Creatinine } \\
(\mathrm{mg} / \mathrm{dl})\end{array}$} & Median & 0.9 & $1.1^{*}$ & 1.15 \\
\hline & Min-Max & $0.8-1.3$ & $0.7-3.9$ & $0.8-5.9$ \\
\hline & $\mathrm{P}$ & & 0.027 & NS \\
\hline & $\mathrm{P}_{1}$ & & & NS \\
\hline \multirow{4}{*}{$\begin{array}{l}\text { Total Protein } \\
(\mathrm{g} / \mathrm{dl})\end{array}$} & Median & 7.65 & 7.3 & $6.9 *$ \\
\hline & Min-Max & $6.8-8.2$ & $6.2-8.4$ & $5.2-9$ \\
\hline & $\mathrm{P}$ & & NS & 0.018 \\
\hline & $\mathrm{P}_{1}$ & & & NS \\
\hline \multirow{4}{*}{$\begin{array}{l}\text { Albumin } \\
(\mathrm{g} / \mathrm{dl})\end{array}$} & Median & 4.5 & $2.9^{*}$ & $2.85 *$ \\
\hline & Min-Max & $4-4.9$ & $2.3-4.7$ & $2-3.8$ \\
\hline & $\mathrm{P}$ & & 0.000 & 0.000 \\
\hline & $P_{1}$ & & & NS \\
\hline
\end{tabular}

Table 3. Serum Values of Alanine Aminotransferase (ALT), Aspartate Aminotransferase (AST), Alkaline Phosphatase (AP), Gamma Glutamyl Transferase (GGT) Activities and Total and Direct Bilirubin of the Studied Groups

\begin{tabular}{|c|c|c|c|c|}
\hline Parameter & Group & Controls(Group I)(n=20) & HCV patients (GroupII) $(n=20)$ & HCC Patients (Group III) $(n=30)$ \\
\hline$\overline{\mathrm{ALT}}$ & Median & 16 & $35.5^{*}$ & $65^{*} \cdot$ \\
\hline \multirow[t]{3}{*}{ (U/L) } & Min-Max & $9-37$ & $6-121$ & $13-273$ \\
\hline & $\mathrm{P}$ & & 0.003 & 0.000 \\
\hline & $\mathrm{P}_{1}$ & & & 0.024 \\
\hline AST & Median & 17 & $53.5^{*}$ & $111.5^{*} \bullet$ \\
\hline \multirow[t]{3}{*}{ (U/L) } & Min-Max & $11-25$ & $10-137$ & $21-364$ \\
\hline & $\mathrm{P}$ & & 0.000 & 0.000 \\
\hline & $\mathrm{P}_{1}$ & & & 0.003 \\
\hline AP & Median & 81 & $122 *$ & $171.5^{*}$ \\
\hline \multirow[t]{3}{*}{ (U/L) } & Min-Max & $36-97$ & $71-408$ & $88-401$ \\
\hline & $\mathrm{P}$ & & 0.000 & 0.000 \\
\hline & $\mathrm{P}_{1}$ & & & NS \\
\hline GGT & Median & 25 & $48.5^{*}$ & $91.5^{*}$ \\
\hline \multirow[t]{3}{*}{ (U/L) } & Min-Max & $16-38$ & $26-200$ & $48-464$ \\
\hline & $\mathrm{P}$ & & 0.000 & 0.000 \\
\hline & $\mathrm{P}_{1}$ & & & 0.003 \\
\hline \multirow{4}{*}{$\begin{array}{l}\text { Total bilirubin } \\
\text { (mg/dl) }\end{array}$} & Median & 0.7 & $1.45^{*}$ & $2.34^{*}$ \\
\hline & Min-Max & $0.4-0.9$ & $0.5-20.1$ & $0.5-34$ \\
\hline & $\mathrm{P}$ & & & 0.000 \\
\hline & $\mathrm{P}_{1}$ & & & NS \\
\hline \multirow{4}{*}{$\begin{array}{l}\text { Dirct bilirubin } \\
(\mathrm{mg} / \mathrm{dl})\end{array}$} & Median & 0.2 & $0.7 *$ & $1.3 *$ \\
\hline & Min-Max & $0.1-0.3$ & $0.1-14.6$ & $0.1-27.1$ \\
\hline & $\mathrm{P}$ & & 0.000 & 0.000 \\
\hline & $\mathrm{P}_{1}$ & & & NS \\
\hline
\end{tabular}

Table 4. Serum Values of Alpha Fetoprotein $(\mathrm{ng} / \mathrm{ml})$ and Survivin $(\mathrm{pg} / \mathrm{ml})$ in the Studied Groups

\begin{tabular}{llccc}
\hline Parameter & Group & Controls (Groupl) $(\mathrm{n}=20)$ & HCV patients(GroupII) $(\mathrm{n}=20)$ HCC Patients $($ GroupIII) $(\mathrm{n}=30)$ \\
\hline AFP & Median & 1.85 & $4{ }^{*}$ & $1,222.5^{*} \cdot$ \\
$(\mathrm{ng} / \mathrm{ml})=$ & Min-Max & $0.8-5.3$ & $1.6-18.1$ & $11.5-40,000$ \\
$(\mu \mathrm{g} / \mathrm{L})$ & $\mathrm{P}$ & & 0.000 & 0.000 \\
& $\mathrm{P}_{1}$ & & & 0.000 \\
Survivin & Median & 13.0 & $13.9^{*}$ & 13.9 \\
$(\mathrm{pg} / \mathrm{ml})$ & Min-Max & $11.0-16.6$ & $12.4-62.0$ & $11.6-125.0$ \\
& $\mathrm{P}$ & & 0.039 & $\mathrm{NS}$ \\
& $\mathrm{P}_{1}$ & & & $\mathrm{NS}$ \\
\hline
\end{tabular}

had shrunken liver, 4 out of $20(20 \%)$ had hepatomegally only, 11 out of $20(55 \%)$ had spleomegaly, 2 out of 20 $(10 \%)$ had periportal fibrosis, 2 out of $20(10 \%)$ had one focal lesion, 1 out of $20(5 \%)$ had portal vein thrombosis and 13 out $20(65 \%)$ had portal hypertension.
In the hepatocellular carcinoma patients group (Group III): 16 out of $30(53.3 \%)$ had enlarged liver with cirrhotic changes, 2 out of $30(6.6 \%)$ had shrunken liver, 4 out of $30(20 \%)$ had hepatomegally only, 16 out of $30(53.3 \%)$ had splenomegally, 21 out of $30(70 \%)$ had periportal 


\section{Research Journal of Applied Biotechnology (RJAB)}

Table 5. Significant Correlations of Survivin in the Studied Groups

\begin{tabular}{lccc}
\hline Group & Parameter & $\mathrm{r}$ & $\mathrm{P}$ \\
\hline Control group & $\mathrm{HB}$ & -0.478 & 0.033 \\
& $\mathrm{Alb}$ & 0.484 & 0.031 \\
& T. BIL & 0.650 & 0.002 \\
& D. Bil & 0.722 & 0.000 \\
HCV Group & ALT & -0.494 & 0.027 \\
(Group II) & & & \\
\hline
\end{tabular}

fibrosis, 14 out of 30 (46.6\%) had one focal lesion, 4 out of $30(13.3 \%)$ had two focal lesions, 1 out of 30 (3.3\%) had three focal lesions, 11 out of 30 (36.6\%) had multiple focal lesions, 6 out of $30(20 \%)$ had portal vein thrombosis, 21 out of 30(70\%) had portal hypertension and 3 out of $30(10 \%)$ had secondaries.

All control subjects were negative for S. mansoni . 11 out of $20(55 \%)$ were positive for S. mansoni in GroupII and 22 out of 30 (73.3\%) in GroupIII.

There was a significant decrease in prothrombin activity in HCVpatients (Group II) and HCC patients (Group III) when each was compared to control group ( $\mathrm{P}=0.000$ for both ) ( Table 1 ).

There was a significant decrease in serum level of total protein in HCC patients(GroupIII) as compared to control group ( $p=0.018)$. There was a significant decrease in serum albumin in HCVand HCC patients (Groups II andIII) when each was compared to the control group (group I) ( $\mathrm{p}=0.000$ for both) (Table 2$)$.

There was a significant increase in ALT, AST, AP and

GGT activities in HCV patients (Group II) when each was compared to the control group and also a significant increase when HCC patients (group III) was compared to control group.But when comparing HCC to HCV patients, only ALT, AST and GGT showed significant increase.

There was a significant increase in serum level of total and direct bilirubin in HCV patients (group II) and HCC patients (group III) when each was compared to the control group ( $\mathrm{p}=0.000$ for all) (Table 3 ).

There was a significant increase in AFP in HCV and HCC patients when each was compared to the control group $(p=0.000$ for both). Also there was a significant increase when HCC patients (group III) was compared with HCV patients (group II) $(\mathrm{p}=0.000) \quad$ (Table 4).There was a significant increase in survivin level in HCV patients (group II) when compared to the $\mathrm{c}$ ontrol group (group I) $(\mathrm{p}=0.039)$ (Table 4).

\section{Discussion}

Regulation of apoptosis (programmed cell death) is important in morphogenesis of human tissues. Impairment of apoptosis is one of the major factors contributing to carcinogenesis. Among the IAP members, Survivin is unique in that it is undetectable in the majority of normal adult tissues (Ito et al., 2000; Bokarewa et al., 2005; Ye et al., 2007). The biological functions of Survivin, other than its antiapoptotic effect, are not well understood in human cancers (Ito et al., 2000).

However, recent studies have defined a role for Survivin in regulating function in normal adult cells suggesting that survivin disruption could have adverse consequences (Fukuda et al., 2006).

Hepatocellular carcinoma (HCC) accounting for about 4.7\% of chronic liver disease in Egypt (Chiou et al., 2007). Several risk factors for $\mathrm{HCC}$ include cirrhosis, hepatitis $B$ and $C$ infections, alcohol abuse, aflatoxin exposure, hemochromatosis and alpha-1 antitrypsin deficiency (Belefer et al., 2002).

It has been reported that not only increased cellular proliferation but also diminished cell death play important roles in hepatocarcinogenesis and tumor progression in HCC (Takehara et al., 2001; Ikeguchi et al., 2002).

Nowadays, there is a need for a biochemical tumor marker that could do better, instead of relying on the traditional marker, AFP with its fallacies in the screening, diagnosis and prognosis of a great number of HCC cases.

To our knowledge, survivin expression has been studied at cellular level and in tissues in patients with HCC but little is known about its serum level in such a disease (Ye et al., 2007).

The aim of the present work is to evaluate the serum level of Survivin in patients with hepatocellular carcinoma associated with hepatitis $\mathrm{C}$ infection and to compare it with its level in patients with chronic hepatitis $\mathrm{C}$ infection. The diagnostic performance of survivin, as a possible tumor marker, is compared to that of serum AFP.

In the present study, the median value of serum Survivin in the control group was $13 \mathrm{pg} / \mathrm{ml}$ (range 11-16.6 $\mathrm{pg} / \mathrm{ml}$ (Bokarewa et al., 2005) found that the plasma level of Survivin in their controls was $121 \pm 2 \mathrm{pg} / \mathrm{ml}$ (mean \pm S.D). Also, (Derin et al., 2008) found that Survivin level in their control group have median value equal $36.2 \mathrm{pg} / \mathrm{ml}$, range equal to $11.6-106 \mathrm{pg} / \mathrm{ml}$. (Gosksel et al., 2007) found that Survivin level among their control group to have median value equal to $68.9 \mathrm{pg} / \mathrm{ml}$, range equal to53.6-102.9 $\mathrm{pg} / \mathrm{ml}$. This variability in Survivin level in healthy adults could be attributed to differences in the groups chosen as regards age, sex, and ethnicity .

The median serum value of Survivin in the hepatitis $\mathrm{C}$ viral infection group (group II) was $13.9 \mathrm{pg} / \mathrm{ml}$ (12.4$62 \mathrm{pg} / \mathrm{ml}$ ). There was a significant increase in Survivin level in HCV patients group (group II) when compared to the control group (group I) ( $\mathrm{p}=0.039)$. (Table 4) This could be explained by increase apoptosis of hepatocytes due to HCV viral infection.

In hepatocellular carcinoma group (group III), Survivin was $13.9 \mathrm{pg} / \mathrm{ml}(11.6-125 \mathrm{pg} / \mathrm{ml})$. There was no significant difference in HCC patients group (group III) when compared to control group (group I) or between HCC group (group III) and HCV group (group II). From this observation, it could be shown that apoptosis due to $\mathrm{HCV}$ infection, decreases by time as the disease progresses.

At tissue level, (Zhu et al., 2005) found that there was a remarkable increase in Survivin expression between the HCCtumor tissue and liver cirrhosis tissues $(\mathrm{P}<0.01)$. Survivin protein was detected in $23(60.5 \%)$ of 38 HCCs and $3(7.9 \%)$ of 38 liver cirrhosis tissues. The expression of survivin in HCC was related to the metastasis of HCC $(\mathrm{P}<0.05)$ by immunohistochemistry and Western blot.

(Yagihashi et al., 2005) found that, in patients with 
Table 6. Cut off Value, Diagnostic Sensitivity, Specificity and Predictive Value of Positive and Negative Results and Efficiency of the Test for Survivin and Alphafetoprotein (AFP)

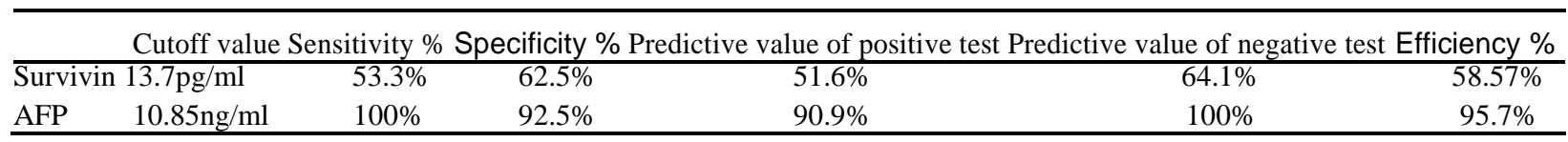

chronic viral hepatitis, elevated anti-survivin antibodies were detected in 10 of 57 sera (17.5\%); and in HCC patients in 7 of 29 sera $(24.1 \%)$. The levels of anti-survivin antibodies in HCC patients with HCV infection were significantly higher than those in the healthy controls and

HCC patients with HBV infection. However, there were no significant differences in the levels of antisurvivin antibodies between $\mathrm{HCV}$ and $\mathrm{HCC}$ patients with HCV infection.

(Montorsi et al., 2007) quantitated survivin mRNA levels by real time RT-PCR in 25 patients. They found that Survivin mRNA was documented in all liver tissues with significantly higher levels in neoplastic specimens $(\mathrm{p}=0.01)$. In non-neoplastic liver tissue, survivin levels were correlated with activity score of chronic liver disease. Increased Survivin levels were correlated with high tumor grade $(\mathrm{p}=0.05)$ and vascular invasion $(\mathrm{p}=0.005)$.

There was a significant correlation between survivin expression and portal vein thrombi and intrahepatic metastatic nodes $(\mathrm{P}<0.05)$ (Ye et al..2007).

(Cui et al., 2008) found that of the $50 \mathrm{HCC}$ specimens, $32(64.0 \%)$ were positive for Survivin expression by immunohistochemistry. Survivin expression was not detected in normal hepatic tissues. and did not correlate to the patients' gender, age, tumor size, degree of differentiation and alpha- fetoprotein level but related to the clinical stage and lymph node metastasis of $\mathrm{HCC}(\mathrm{P}<0.05)$.

Regarding the work done by immunohistochemical method by (Hui et al., 2008) they found that Survivin protein was expressed in the cytoplasm in 30 of 42 cases of HCC $(71.4 \%)$ and in 4 of 34 cases of adjacent cirrhosis tissues (11.8\%) . Expression of Survivin protein was negative in 10 cases of normal tissues. Protein positive expression rate in $\mathrm{HCC}$ was significantly higher than adjacent cirrhosis tissues and normal tissues $(\mathrm{P}<0.001)$.

As regards serum AFP which is considered a valuable tumor marker in the diagnosis and prognosis of HCC despite pitfalls in its diagnostic performance, the present work demonstrated sharply elevated highly significant serum AFP in the HCC group compared to the other two groups $(\mathrm{p}=0.000$ for both). Furthermore, despite being within the safely reported reference intervals, yet the present work demonstrated a significantly higher AFP median value in HCV group compared to the control group. This goes in concordance with many studies reporting the same finding in HCC and HCV groups compared to the control group (Takehara et al., 2001; Ezzat S et al., 2005).

(Tong et al., 2001), pointed to many pitfalls of AFP as a tumor marker, particularly in its degree of diagnostic specificity and sensitivity, being altered in benign and malignant conditions. The pursuit for a potentially new biochemical marker for the prediction and diagnosis of HCC was carried out in the present work by the measurement of plasma Survivin.

(Filmus et al., 2004) found that the only serological marker currently widely used for the diagnosis of HCC is AFP. However, the sensitivity of this marker is limited (41-65\%). Given the high heterogeneity of HCC, it is currently thought that an optimal serological test for HCC will be based on the simultaneous measurement of two or three highly specific serological markers .

When comparing the diagnostic performance of plasma Survivin as a possible tumor marker in HCC to the well established HCC marker serum AFP, receiver operating characteristics (ROC) curves were done and the best generated cut off values for both AFP and survivin were $10.85 \mathrm{ng} / \mathrm{ml}$ and $13.7 \mathrm{pg} / \mathrm{ml}$ respectively. We came to a conclusion that serum AFP still surpassed plasma survivin due to the higher degree of both diagnostic specificity , sensitivity, positive and negative predictive value as well as efficiency (se Table 6).

From the present work it could be concluded that : 1) Serum Survivin showed higher values in HCV group compared to controls; 2) Serum AFP showed a better diagnostic performance and proved to be more reliable as a tumor marker for HCC.

\section{References}

Altieri DC, Marchisio C (1999). Survivin apoptosis: an interloper between cell death andcell proliferation in cancer. Lab Invest, 79, 1327-33.

Asanuma H, Torigoe T, Kamiguchi K, et al (2005). Survivin expression is regulated by coexpression of human epidermal growth factor receptor- 2 and epidermal growth factor receptor via phosphatidylinositol 3-Kinase/AKT signaling pathway in breast cancer cells. Cancer Res, 65, 11018-25.

Befeler AS, Di Bisceglie AM (2002). Hepatocellular carcinoma : diagnosis and treatment. Gastroenterology, 122, 1609-19.

Bishop ML, Fody EP, Schoeff L (2005). Clinical chemistry. principle, procedures, correlations. 5th Ed. Lippincott Williams \& Wilkins. United States of America, 152-3, 156

Bokarewa M, Lindblad S, Bokarew D, et al (2005). Balance between survivin, a key member of the apoptosis inhibitor family, and its specific antibodies determines erosivity in rheumatoid arthritis. Arthritis Res Ther, 7, R349-58.

Bosch FX, Ribes J, Cleries R, et al (2005). Epidemiology of hepatocellular carcinoma. Clin Liver Dis, 9, 191- 211.

Burtis CA, Ashwood ER, Bruns DE (2006). Tietz textbook of clinical chemistry and molecular diagnostics. 4th Ed. Elsevier Saunders Company. Philadelphia, 798, 586-7, 548, 1195-8, 604-7, 609-10, 613, 717, 1801-3, 547, 608.

Chang JT, Wong F-H, Liao C-T, et al (2004). Enzyme immunoassay for serum autoantibody to survivin and its findings in head-and-neck cancer patients. Clin Chem, 50, 1261-4.

Chiou S-K, Mandayam S (2007). NSAIDs enhance proteasomic degradation of Survivin a mechanism of gastric epithelial 


\section{Research Journal of Applied Biotechnology (RJAB)}

cell injury and apoptosis. Biochem Pharmacol, 74, 1485-95 . Cui F, Chen B, Chen JZ, et al (2008). Expressions of Survivin and vascular endothelial growth factor in hepatocellular carcinoma and their clinical significance. Nan Fang Yi Ke Da Xue Xue Bao, 28, 761-3.

Derin D, Soydinç HO, Guney N, et al (2008). Serum levels of apoptosis biomarkers, survivin and TNF-alpha in non small cell lung cancer. Lung Cancer, 59, 240-5.

Di Maio M, Daniiele B, Pignata S, et al (2008). Is human hepatocellular carcinoma a hormone-responsive tumor? World J Gastroenterol, 14, 1682-9.

Duffy MJ, O'Donovan N, Brennan DJ, et al (2007). Survivin : a promising tumor biomarker. Cancer Lett, 249, 49-60.

El-Zayadi AR, Abaza H, Shawky S, et al (2001). Prevalence and epidemiological features of hepatocellular carcinoma in Egypt-a single center experience. Hepatol Res, 19, 170-9.

Ezzat S, Abdel-Hamid M, Eissa SA, et al (2005). Associations of pesticides, $\mathrm{HCV}, \mathrm{HBV}$, and hepatocellular carcinoma in Egypt. Int J Hyg Environ Hlth, 208, 329-39 .

Feldman M, Friedman LS, Sleisenger MH (2002). Sleisenger \& Fordtrans. Gastrointestinal and liver disease. 7th Ed. WB Saunders Company. Philadelphia, 1263, 1303, 588.

Fields AC, Cotsonis G, Sexton D, et al (2004). Survivin expression in hepatocellular carcinoma: correlation with proliferation, prognostic parameters and outcome. Mod Pathol, 17, 1378-85.

Filmus J, Capurro M (2004). Glypican-3 and alphafetoprotein as diagnostic tests for hepatocellular carcinoma. Mol Diagn, 8, 207-12.

Fukuda S, Pelus LM (2006). Survivin, a cancer target with an emerging role in normal adult tissues. Mol Cancer Ther, 5, 1087-98.

Goksel G, Tanelif F, Uslu R, et al (2007). Serum her2/neu and survivin levels and their relationship to histological parameters in early-stage breast cancer. $J$ Int Med Res, 35, 165-72.

Hui W, Zan Y, Wang X, et al (2008). Expression of Survivin, p53 and its relationship with apoptosis, proliferation in hepatocellular carcinoma(HCC). J Nanjing Med Univ, 22, 255-9.

Ikeguchi M, Hirooka Y, Kaibara N (2002). Quantitative analysis of apoptosis-related gene expression in hepatocellular carcinoma. Cancer, 95, 1938-45.

Ito T, Shirakiki K, Sugimoto K, et al (2000). Survivin promotes cell proliferation in human hepatocellular carcinoma. Hepatology, 31, 1080-5.

Kappler M, Kotzsch M, Bartel F, et al (2001). Elevated expression level of survivin protein in soft tissue sarcomas is a strong independent predictor of survival. Int $J$ Cancer, 95, 360-72.

Kobayashi Y, Yukiue H, Sasaki H, et al (2002). Developmentally regulated expression of survivin in human thymus. Human Immun, 63, 101-7.

Lewis SM, Bain BJ, Bates I (2001). Dacie and Lewis. Practical Hematology Textbook. 9th Ed. Harcourt publishers limited. London, 30-41.

Mamori S, Asakura T, Ohkawa K, et al (2007). Survivin expression in hepatocellular carcinoma and post-treatment with anti-cancer drug under hypoxic culture Condition. World J Gastroenterol, 13, 5306-11.

Montorsi M, Maggioni M, Falleni M, et al (2007). Survivin gene expression in chronic liver disease and hepatocellular carcinoma. Hepatogastroenterology, 54, 2040-4.

Parkin DM (2000). Global cancer statistics in the year 2000. Lancet Oncol, 2, 533-43.

Sarela AI, Macadam RC, Farmery SM, et al (2000). Expression of the antiapoptosis gene, survivin, predicts death from recurrent colorectal carcinoma. Gut, 46, 645-50. Takehara

T, Liu X, Fujimoto J, et al (2001). Expression and role of Bcl- xL in human hepatocellular carcinomas. Hepatology, 34, 55-61.

Tong M, Blatt L, Kao V (2001). Surveillance for hepatocellular carcinoma in patients with chronic viral hepatitis in the United States of America. $J$ Gastroenterol Hepatol, 16, 553-9.

Trinder P. Ann Clin Biochem 1969 ; 6: 24 (Quoted from Varley H, Gowenlock AH and Bell M (eds). Practical Clinical Biochemistry. $5^{\text {th }}$ Ed. Heinmann Medical Books Ltd. London 1980, 405.

Vetter CS, Muller-Blech K, Schrama D, et al (2005). Cytoplasmic and nuclear expression of survivin in melanocytic skin lesions. Arch Dermatol Res, 297, 26-30.

Wang Y, Suominen J, Hakovirta H, et al (2004). Survivin expression in rat testis is up-regulated by stem cell factor. Mol Cell Endocrinol, 218, 165-74 .

Yagihashi A, Asanuma K, Kobayashi D, et al (2005). Autoantibodies to survivin in patients with chronic hepatitis and hepatocellular carcinoma. Autoimmunity, 38, 445-8.

Ye C-P, Qiu C-Z, Huang Z-X, et al (2007). Relationship between survivin expression and recurrence, and prognosis in hepatocellular carcinoma. World J Gastroenterol, 13, 6264-8.

Zhu H, Chen X-P, Zhang W-G, et al (2005). Expression and significance of new inhibitor of apoptosis protein survivin in hepatocellular carcinoma. World J Gastroenterol, 11, 3855-9. 
Research Journal of Applied Biotechnology (RJAB) 